UDC 538.945

\title{
ABOUT EXPERIMENTAL DISCOVERY OF TYPE II SUPERCONDUCTIVITY
}

\author{
A. Shepelev \\ National Science Center "Kharkov Institute of Physics and Technology”, Kharkiv, Ukraine \\ E-mail: shepelev@kipt.kharkov.ua
}

The date and authorship of the experimental discovery of the phenomenon of type II superconductivity is specified.

"It is a fascinating testament to Shubnikov's great originality and to the terrible times that deprived him of his life and we all of the fruits of the science for so long. Even now, many do not really understand the breakthrough made in Kharkov".

From the letter of 31 December, 2008, written by Shubnikov Professor D. Larbalistier, Director of Applied Superconductivity Center, USA, on reprinting in English the article [1].

At present Type II superconductors (Shubnikov phase) enjoy wide applications. Of particular importance to the history of science are publications devoted to the tragic and intricate history of the experimental discovery of the phenomenon of Type II superconductivity in Kharkov in 1936.

Recently an interesting book has been published by L.J. Reinders [2], in which unfortunately the essence of the discovery of Type II superconductivity phenomenon is presented incorrectly (just as previously this was erroneously described in [3] and [4]).

In [2], [3], and [4] it was stated (with references to articles of 1935 [5]) that Type II superconductivity was due to the presence of two critical magnetic fields $\mathrm{H}_{\mathrm{c} 1}$ and $\mathrm{H}_{\mathrm{c} 2}$ (i.e., the fields of beginning/termination of the breakup of superconductivity, respectively).

In fact the presence of two critical magnetic fields in superconducting alloys was noted back in 1929-1931 by W.J. De Haas and J. Voogd in their investigations of electrical properties of polycrystals in a magnetic field [6]. As for the manifestation of the presence of the two fields in the magnetic properties of polycrystals of alloys, this was first reported by W.J. De Haas and J.M. Casimir-Jonker on December 22, 1934 at the session of the Royal Academy, Amsterdam [7] (see also their other publications [8]). This special feature was later (1935) confirmed by J.N. Rjabinin and L.V. Shubnikov [5], and also, by K. Mendelssohn and J.R. Moore [9].

However, all those authors did not exclude the possibility of the heterogeneus phase composition of the alloys that could cause the existence of two critical magnetic fields.

Only in the investigations of L.V. Shubnikov, V.I. Khotkevich, G.D. Shepelev, J.N. Rjabinin [1, 10], which were performed on carefully prepared singlephase single crystals of alloys, it was first discovered that with increasing concentration of impurities a dramatic change in the properties occurred, viz., Type I superconductor transforms to Type II superconductor (details are given in [11]). That's exactly why the Memorial plaque about the discovery by the abovementioned 4 authors was placed on the building of our Institute. The dissertation of G.D. Shepelev [12], completed in 1935-1936 under the leadership of L.V. Shubnikov at the Cryogenic Laboratory of the Ukrainian Institute of Physics and Technology (now National Science Center "Kharkov Institute of Physics and Technology"), in fact, was the first dissertation in the world on Type II Superconductivity.

The critical value used to determine the superconductor type is the Ginzburg-Landau parameter

$$
æ_{c}=1 / \sqrt{2} \quad[13] .
$$

At the time when V.L. Ginzburg and L.D. Landau created their theory of superconductivity [13], all superconductors were commonly assumed to have positive n-s interface energy and

$$
æ<æ_{\mathrm{c}} .
$$

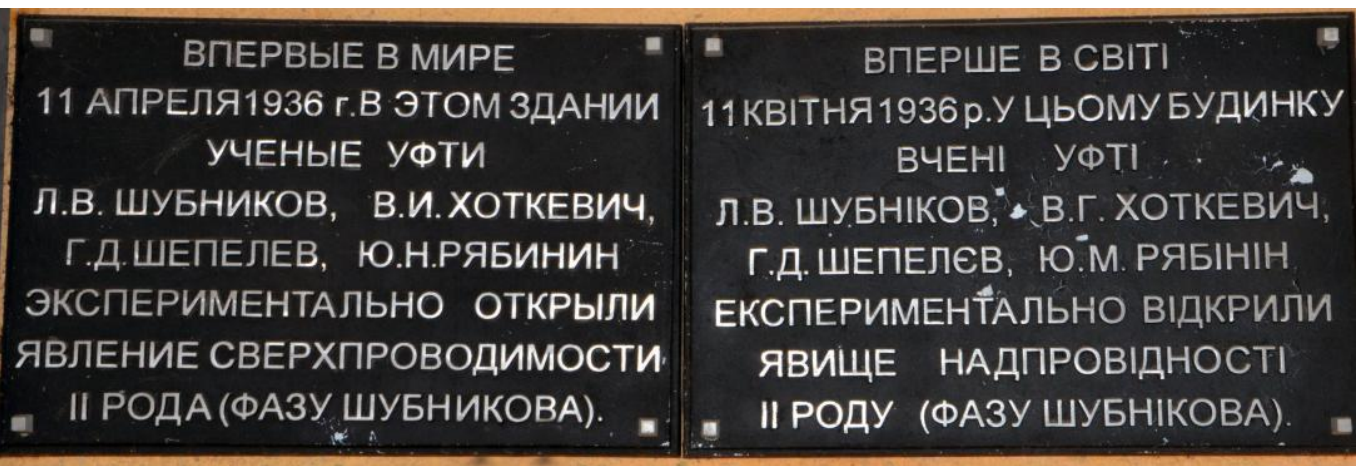


As V.L. Ginzburg indicated [14], with time, L.D. Landau put forward the idea that in superconducting alloys $æ>æ_{c}$ and the n-s interface energy is negative. Indeed, the recent superconductors, discovered for the last 60 years, starting from $\mathrm{Nb}_{3} \mathrm{Sn}$ [15] and up to HTSC cuprates, fullerenes, organic materials, $\mathrm{MgB}_{2}$ and ferrum-based systems all these are the Type II superconductors!

At the International Conference on the Science of Superconductivity (Colgate University, Hamilton, New York, 1963) about 350 participants came to the conclusion: "It should be noted that our theoretical understanding of type II superconductors is due to Landau, Ginzburg, Abrikosov, and Gor'kov, and that the first definitive experiments were carried out as early as 1937 by Shubnikov" - John Bardeen, University of Illinois (Conference Chairman), Roland W. Schmitt, General Electric Research Laboratory (Conference Secretary") [16].

\section{ACKNOWLEDGEMENTS}

The author is grateful to Academician V.L. Ginzburg, Academician A.A. Abrikosov, Academician N.F. Shul'ga, and Professor D. Larbalestier for interesting discussions.

\section{REFERENCES}

1. L.V. Shubnikov, V.I. Khotkevich, Yu.D. Shepelev, Yu.N. Riabinin. Magnetic properties of superconducting metals and alloys // Zh. Exper. Teor. Fiz. (USSR). 1937, v. 7, N 2, p. 221-237; Ukrainian Journal of Physics, Special issue 2008, v. 53, p. 42-52.

2. L.J. Reinders. The Life, Science and Times of Lev Vasilievich Shubnikov. Pioneer of Soviet Cryogenics. Springer, 2018, p. 125.

3. B.I. Verkin, V.G. Manzhely, Ju.A. Khramov, O.N. Trapeznikova, S.A. Gredeskul, L.A. Pastur, Ju.A. Freiman, V.G. Gavrilko, L.K. Snigireva (Eds.). L.V. Shubnikov - Selected Works. Reminiscences. Kyiv: “Ukrainian Academy of Sciences", 1990, p. 16, 29.

4. P.F. Dahl. Superconductivity. Its Historical Roots and Development from Mercury to the Ceramic Oxides // N.Y.: "American Institute of Physics", 1992, p. 216-219.

5. J.N. Rjabinin, L.W. Schubnikow. Magnetic properties and critical currents of superconducting alloys // Phys. Z. Sowjet. 1935, v. 7, N 1, p. 122-125; Nature. 1935, v. 135, N 3415, p. 581-582.

6. W.J. De Haas, J. Voogd. Disturbance of the superconductivity of the compound $\mathrm{Bi}_{5} \mathrm{Tl}_{3}$ and of the alloys Sn-Bi and Sn-Cd by magnetic fields // Comm. Phys. Lab. Univ. Leiden. 1929, v. 18, N 199c, p. 31-40; The influence of magnetic fields on supraconductors // Ibid. 1930, v. 19, N 208b, p. 9-20; Further investigations on the magnetic disturbance of the superconducting alloys // Ibid. 1931, v. 19, N 214b, p. 9-16.

7. W.J. De Haas, J.M. Casimir-Jonker. Penetration of magnetic field into supraconductive alloys // Proc. Roy. Acad. Amsterdam, Proc. Sec. Sci. 1935, v. 38, N 1, p. 2-7.

8. W.J. De Haas, J.M. Casimir-Jonker. Penetration of magnetic field into supraconductive alloys // Nature. 1935, v. 135, N 3401, p. 30-31; Comm. Phys. Lab. Univ. Leiden. 1935, v. 21, N 233c, p. 1-7.

9. K. Mendelssohn, J.R. Moore. Supra-conducting alloys // Nature. 1935, v. 135, N 3420, p. 826-827.

10. L.W. Schubnikow, W.I. Chotkewitsch, J.D. Schepelew, J.N. Rjabinin. Magnetische Eigenschaften supraleitender Metalle und Legierungen // Sondernummer Phys. Z. Sowjet. Arbeiten auf dem Gebiete tiefer Temperaturen. Juni 1936, p. 39-66; Phys. Z. Sowjet. 1936, v. 10, H2, p. 165-192.

11. A.G. Shepelev. The Discovery of Type II Superconductors (Shubnikov Phase) in: Superconductor (ed. Adir Moyses Luiz), Rijeka: "SCIYO". 2010, p. 17-46; www.intechopen.com/books/show/title/superconductor; A. Shepelev. Alloyed Superconductor Type I and Type II Transition and the Collective Failure to Understand It // 100 Years of Superconductivity / Ed. H. Rogalla and P.H. Kes. London, New York, Boca Raton: "CRC Press, Taylor \& Francis Group”, 2012, p. 630-634.

12. G.D. Shepelev. Magnetic properties of supurconducting alloys. Kharkov State Univ., 1938.

13. V.L. Ginzburg, L.D. Landau. On the theory of superconductivity // Zh. Exper. Teor. Fiz. (USSR). 1950, v. 20, N 12, p. 1064-1082.

14. V.L. Ginzburg. The current state of the theory of superconductivity // Uspekhi Fiz. Nauk (USSR). 1952, v. 48, N 1, p. 102.

15. J.E. Kunzler, E. Buehler, P.S.L. Hsu, J.H. Wernick. Superconductivity in $\mathrm{Nb}_{3} \mathrm{Sn}$ at hight current density in a magnetic field of 88 kgauss // Phys. Rev. Letts. 1961, v. 6, N 3, p. 89-91.

16. J. Bardeen, R.W. Schmitt. International conference on the science of superconductivity // Revs. Mod. Phys. 1964, v. 36, N 1, Pt. 1, p. 2.

Article received 24.11.2021

\title{
ОБ ЭКСПЕРИМЕНТАЛЬНОМ ОТКРЫТИИ ЯВЛЕНИЯ СВЕРХПРОВОДИМОСТИ II РОДА
}

\author{
А. Шепелев
}

Уточняется дата и авторство экспериментального открытия явления сверхпроводимости II рода.

\section{ПРО ЕКСПЕРИМЕНТАЛЬНЕ ВІДКРИТТЯ ЯВИЩА НАДПРОВІДНОСТІ ІІ РОДУ}

\section{А. Шепелєв}

Уточнюється дата і авторство експериментального відкриття явища надпровідності II роду. 